\title{
BMJ Open Maternal use of cough medications during early pregnancy and selected birth defects: a US multisite, case- control study
}

\author{
Yanyan Cao, ${ }^{1}$ Anthony Rhoads, ${ }^{1}$ Trudy Burns, ${ }^{1}$ Ryan M Carnahan, ${ }^{1}$ \\ Kristin M Conway, ${ }^{1}$ Martha M Werler, ${ }^{2,3}$ Allen Mitchell, ${ }^{2}$ Paul Romitti (1) ${ }^{1}$
}

To cite: Cao Y, Rhoads A, Burns T, et al. Maternal use of cough medications during early pregnancy and selected birth defects: a US multisite, case-control study. BMJ Open 2021;11:e053604. doi:10.1136/ bmjopen-2021-053604

- Prepublication history and additional supplemental material for this paper are available online. To view these files, please visit the journal online (http://dx.doi.org/10.1136/ bmjopen-2021-053604).

Received 19 May 2021 Accepted 01 December 2021

Check for updates

(c) Author(s) (or their employer(s)) 2021. Re-use permitted under CC BY-NC. No commercial re-use. See rights and permissions. Published by BMJ.

${ }^{1}$ Department of Epidemiology, The University of lowa, lowa City, lowa, USA

${ }^{2}$ Slone Epidemiology Center, Boston University, Boston, Massachusetts, USA

${ }^{3}$ Department of Epidemiology, Boston University, Boston, Massachusetts, USA

Correspondence to Dr Paul Romitti; paul-romitti@uiowa.edu

\section{ABSTRACT}

Objective To examine associations between maternal use of cough medications containing dextromethorphan (DM) without guaifenesin (glyceryl guaiacolate (GG)) ('DM alone'), $\mathrm{GG}$ without $\mathrm{DM}$ ('GG alone') or $\mathrm{DM}+\mathrm{GG}$ and major birth defects in offspring.

Design Population-based case-control study.

Setting The multisite, US National Birth Defects Prevention Study.

Participants Mothers of 1644 children with neural tube defects (NTDs), 15110 with non-NTDs, and 10671 control children without a birth defect diagnosis.

Main outcome measures ORs and 95\% Cls.

Results For NTD analysis, $1.7 \%$ of mothers of case children and $1.2 \%$ of mothers of control children reported using DM alone, $1.1 \%$ and $0.6 \% \mathrm{GG}$ alone, and $0.4 \%$ and $0.2 \% \mathrm{DM}+\mathrm{GG}$. Respective percentages for non-NTD analysis were $2.2 \%$ and $1.9 \%$ for DM alone, $1.7 \%$ and $1.6 \%$ for $\mathrm{GG}$ alone, and $0.5 \%$ and $0.4 \%$ for $\mathrm{DM}+\mathrm{GG}$. For all NTDs and subtypes, adjusted OR estimates for DM alone were near the null with $95 \%$ Cls that included 1.0 . Estimates $(95 \% \mathrm{Cl})$ were 1.8 (1.0 to 3.3) for $\mathrm{GG}$ alone and 1.8 (0.6 to 4.8) for $\mathrm{DM}+\mathrm{GG}$ with all NTDs and 2.2 (1.1 to 4.3 ) for $G G$ alone with spina bifida. Of the 45 adjusted OR estimates for non-NTDs, 39 ranged from 0.5 to 1.6 with $95 \%$ Cls that included 1.0. Near twofold or higher estimates $(95 \% \mathrm{Cl})$ were observed for the remainder and included 1.9 (1.0 to 3.7) for hydrocephalus, 2.9 (1.3 to 6.5) for atrioventricular septal defect and 1.8 (1.1 to 3.0) for transverse limb deficiency with DM alone; 2.1 (1.1 to 4.0) for small intestinal atresia/stenosis and 2.1 (0.9 to 4.5) for omphalocele with GG alone; and 3.2 (1.5 to 6.9) for gastroschisis with $\mathrm{DM}+\mathrm{GG}$.

Conclusions Maternal use of medications containing DM alone, $\mathrm{GG}$ alone or $\mathrm{DM}+\mathrm{GG}$ showed positive associations with a small number of birth defects. These observations, which should be interpreted with caution due to small proportions of exposed mothers, may represent true signals or chance findings and warrant evaluation in future studies.

\section{INTRODUCTION}

The most recent USA study, although dated, estimated that maternal use of cough medications any time during pregnancy was $8.8 \%$,
Strengths and limitations of this study

- This large, population-based case-control study included case children whose birth defect diagnoses were systematically classified by clinical geneticists and a random sample of unaffected control children identified from 10 US population-based surveillance programmes.

- Trained interviewers conducted a structured telephone interview with mothers of case and control children to obtain information about several exposures, including medications used shortly before and during pregnancy.

- Retrospective interview reports can introduce the potential for missing or incorrect maternal reporting of exposure and for recall bias; however, our use of specific prompts for medications and treatments has been shown to produce more complete postpregnancy reporting.

- The frequency of use, but not the dose, was requested from mothers, which precluded our ability to estimate associations by total dose of medication exposure.

with $3.5 \%$ of mothers reportedly using these medications during the first trimester of pregnancy. ${ }^{1}$ Of concern, use of these medications may increase with the emergence of SARSCoV-2 and COVID-19. Dextromethorphan $(\mathrm{DM})$, an antitussive, and guaifenesin (glyceryl guaiacolate $(G G)$ ), an expectorant used to loosen phlegm, are two of the main active components in over the counter (OTC) cough medications, but information on their potential teratogenic effects is limited and inconsistent.

Animal data for DM showed that exposure of zebrafish embryos to DM induced mouth and jaw malformations, ${ }^{2}$ and exposure of avian embryos to N-methyl-D-aspartate receptor antagonists, including DM, induced defects of the neural crest and neural tube. ${ }^{3}$ However, experiments in rat and rabbit 
embryos exposed to DM and summarised by Brent ${ }^{4}$ reportedly did not increase the occurrence of malformations. The only animal study, to our knowledge, involving GG reported decreased fetal weight and impaired skeletal development in fetuses of exposed female rats. ${ }^{5}$

Available studies involving humans were based on small sample sizes and produced data that were inconclusive for offspring of mothers who reported prenatal use of DM, ${ }^{6-10}$ $\mathrm{GG}^{8911}$ or any cough medication. ${ }^{12}$ Some studies have reported imprecise or weak associations between DM and hydrocephalus, ${ }^{6}$ cleft palate, ${ }^{6}$ gastroschisis ${ }^{8}$ and hypospadias. ${ }^{9}$ Other studies have reported associations between maternal use of GG during pregnancy and neural tube defect (NTD) affected pregnancies (anencephaly, spina bifida cystica, craniorachischisis or iniencephaly) ${ }^{11}$ or between any cough medication use and spina bifida or hydrocephalus. ${ }^{12}$

Secondary data sources, such as third-party payer databases or electronic medical records, do not typically or systematically include information on exposure to OTC medications. As such, we used primary data collected for the National Birth Defects Prevention Study (NBDPS), a multistate, population-based case-control study in the USA, to investigate whether associations exist between maternal use of cough medications containing DM without GG (DM alone), GG without DM (GG alone) or both $(\mathrm{DM}+\mathrm{GG})$ during early pregnancy and over 20 major birth defects.

\section{MATERIAL AND METHODS Study sample}

Our case-control analysis used data for children with estimated dates of delivery during October 1997-December 2011 and enrolled from 10 US sites (Arkansas, California, Georgia, Iowa, Massachusetts, New Jersey, New York State, North Carolina, Texas and Utah).

NBDPS methods are detailed elsewhere. ${ }^{13}$ Case children were live births, stillbirths and elective terminations of pregnancies with a diagnosis of at least 1 of more than 30 major structural birth defects. Standardised case definitions with confirmatory diagnostic procedures were developed for each defect and used to guide abstraction of clinical data from medical records by the birth defect surveillance programme at each site; abstracted data were reviewed by clinical geneticists. ${ }^{14}$ Case children were classified as those with isolated (no additional major defect in another organ system) or multiple (one or more additional major defects in another organ system) birth defects. Case children with defects attributed to a known genetic syndrome or secondary to another defect were excluded.

Control children were live births without a diagnosed birth defect; these children were randomly selected from birth certificates or birth hospital logs. ${ }^{13}$ Control children were residents of the same geographic regions and were delivered during the same calendar years as case children. For each calendar year, approximately
100 control children were recruited per site, allowing a 1:1 ratio (minimum) between control children and case children with an NBDPS-eligible defect. Case or control children were excluded from NBDPS if their mother had participated in the study with a previous pregnancy, could not complete the interview in English or Spanish or was incarcerated or otherwise did not have legal custody of the child at the time of the interview. Overall, NBDPS enrolled more than 43000 mothers of case and control children.

\section{Interview data collection}

A systematic protocol was used to conduct the NBDPS telephone interview with mothers of case and control children 6 weeks through 24 months after their estimated date of delivery. ${ }^{13}$ The average time to interview was 11.7 months for case and 9.5 months for control mothers. ${ }^{15}$ The structured interview asked about sociodemographic characteristics along with lifestyle and dietary factors, environmental and occupational exposures, and medical conditions, including medications used, shortly before and during pregnancy. Online supplemental table 1 lists items queried for an example indication episode (cold or influenza) and concomitant medication use for the episode. Mothers were asked to provide the medication name and the full start and stop dates (month, day and year) for each use of a medication. If a mother was unable to recall the full start or stop dates, she was asked to provide the pregnancy month or calendar month when the medication was used; whether the start and stop dates occurred at the beginning, middle or end of a reported month; and the duration of use of the medication. The frequency of use, but not the dose, was requested, which precluded our ability to estimate associations by total dose of medication exposure.

\section{Cough medication exposure}

We examined maternal reports of cough medication use during 3 months before conception through the end of pregnancy for any indication. The active components in each reported medication were coded using the Boston University Slone Epidemiology Center Drug Dictionary. ${ }^{16}$ Reported use of a medication containing DM alone, GG alone or DM +GG was examined to assess whether use occurred during the critical exposure period (relevant gestational developmental period), defined as the month before pregnancy (B1) through the first pregnancy month (P1) for analysis of NTDs and through the third pregnancy month (P3) for analysis of non-NTDs. To accomplish this, we used a detailed exposure algorithm to estimate start and stop dates of medication use when partial timing information was reported (online supplemental table 2, online supplemental box 1).

We defined mothers as exposed if they reported using one or more medications containing DM alone, GG alone or DM +GG during a critical exposure period. Mothers who reported using at least one medication containing DM alone and at least one containing GG alone during 
a critical exposure period were defined as exposed to $\mathrm{DM}+\mathrm{GG}$ and excluded from analysis of DM alone or GG alone. Mothers who reported using no medications containing DM or GG during the 3 months before pregnancy and during each month of their pregnancy were defined as unexposed. Mothers were not classified as exposed or unexposed if they reported using a medication containing DM or GG outside of a critical exposure period or if they did not report sufficient information on timing of exposure to these medications. Because we lacked information on medication dose, we examined exposure dichotomously for each cough medication component.

\section{Analytical sample}

Overall, 32017 mothers of case children and 11829 mothers of control children with estimated dates of delivery during October 1997-December 2011 completed the NBDPS interview, representing participation percentages of $67 \%$ and $65 \%$ for mothers of case and control children, respectively. As shown in figure 1, we excluded mothers of case children classified as having multiple birth defects and of those with heart defects not classified as simple (anatomically discrete or a well-recognised single cardiac defect) ${ }^{17}$ to improve the homogeneity of the defect groups studied. We excluded pregnancies with a plurality of two or more or with unreported plurality and mothers with type 1 , type 2 or an unreported type of diabetes diagnosed before delivery or with an unreported diagnosis date. For the analysis of NTDs, we excluded mothers who reported using folate antagonist medications (carbamazepine, cholestyramine resin, methotrexate, oxcarbazepine, sulfasalazine, triamterene, trimethoprim, phenytoin or phenobarbital) during B1 or P1, based on previous findings of associations of these medications with NTDs. ${ }^{18}$ In addition, mothers were excluded from analysis if they reported using DM or GG outside the relevant critical exposure period or reported insufficient information to classify use of DM or GG. Birth defects were included in the analysis if there were 100 or more isolated cases and five or more exposed case mothers. After these exclusions, maternal interview data were available for 1644 case children and 10409 control children for analysis of NTDs and for 15110 case children and 10671 control children for analysis of non-NTDs.

\section{Statistical analysis}

Several child and maternal characteristics and exposures shown in previous NBDPS investigations to be associated with major birth defects were selected, and proportions with these characteristics and exposures were calculated (tables 1 and 2). These characteristics and exposures included child sex, first-degree family history of the same defect and study site; maternal race/ethnicity, age and educational level at delivery, prepregnancy body mass index and hypertension diagnosed before or during pregnancy; and maternal cigarette smoking, alcohol consumption, fever and use of a supplement containing folic acid during the relevant exposure period for NTDs or nonNTDs. Unconditional logistic regression analysis was used to estimate crude ORs (cORs) and corresponding 95\% CIs for associations between maternal exposure during B1P1 to DM alone, GG alone or DM +GG and NTDs and associations between each medication exposure during B1P3 and non-NTDs. Using the characteristics and exposures as covariates, we estimated adjusted ORs (aORs) and $95 \%$ CIs for each medication exposure. Children or mothers with missing data for at least one characteristic or exposure were removed from the adjusted analysis. To examine the potential for confounding by indication, we estimated cORs and aORs and corresponding 95\% CIs for maternal respiratory symptoms (eg, cough, congestion and runny nose) during a critical exposure period among mothers unexposed to DM or GG. All data analyses were conducted using SAS statistical software, V.9.4 (SAS Institute).

\section{Patient and public involvement}

Each participating site in the NBDPS was awarded a cooperative agreement from the National Center for Birth Defects and Developmental Disabilities (formerly the Center for Birth Defects Research) at the USA Centers for Disease Control and Prevention. The Center was established in 1996 through a federal legislative mandate with funding for the Center formalised through the Birth Defects Prevention Act of 1998. The Center determined the birth defect outcomes to include in the NBDPS, and investigators from each participating site jointly developed the eligibility criteria, research questions and recruitment protocols; thus, mothers of case and control children were not involved with the design, recruitment and conduct of the study. When obtaining informed consent, study staff provided mothers with an estimate of the time commitment required to participate in the NBDPS. Using an open-ended question in the closing section of the NBDPS interview, participants were asked to identify any factors, including those mentioned in the interview, that they thought might cause birth defects. Investigators from the Center and participating sites lead the dissemination of NBDPS results, largely through scientific presentations and publications, as well as through summaries posted on the NBDPS public website (http://nbdps.org) and through annual newsletters that were made available to study participants.

\section{RESULTS}

Proportions of maternal and child covariates for the 1644 case children with NTDs and 10409 control children are listed in table 1, and those for the 15110 case children with non-NTDs and 10671 control children are listed in table 2. Covariates for NTD subtypes are listed in online supplemental table 3, and those for individual non-NTDs are listed in online supplemental tables 4-9. The frequencies of missing data observed for most covariates examined were low. 


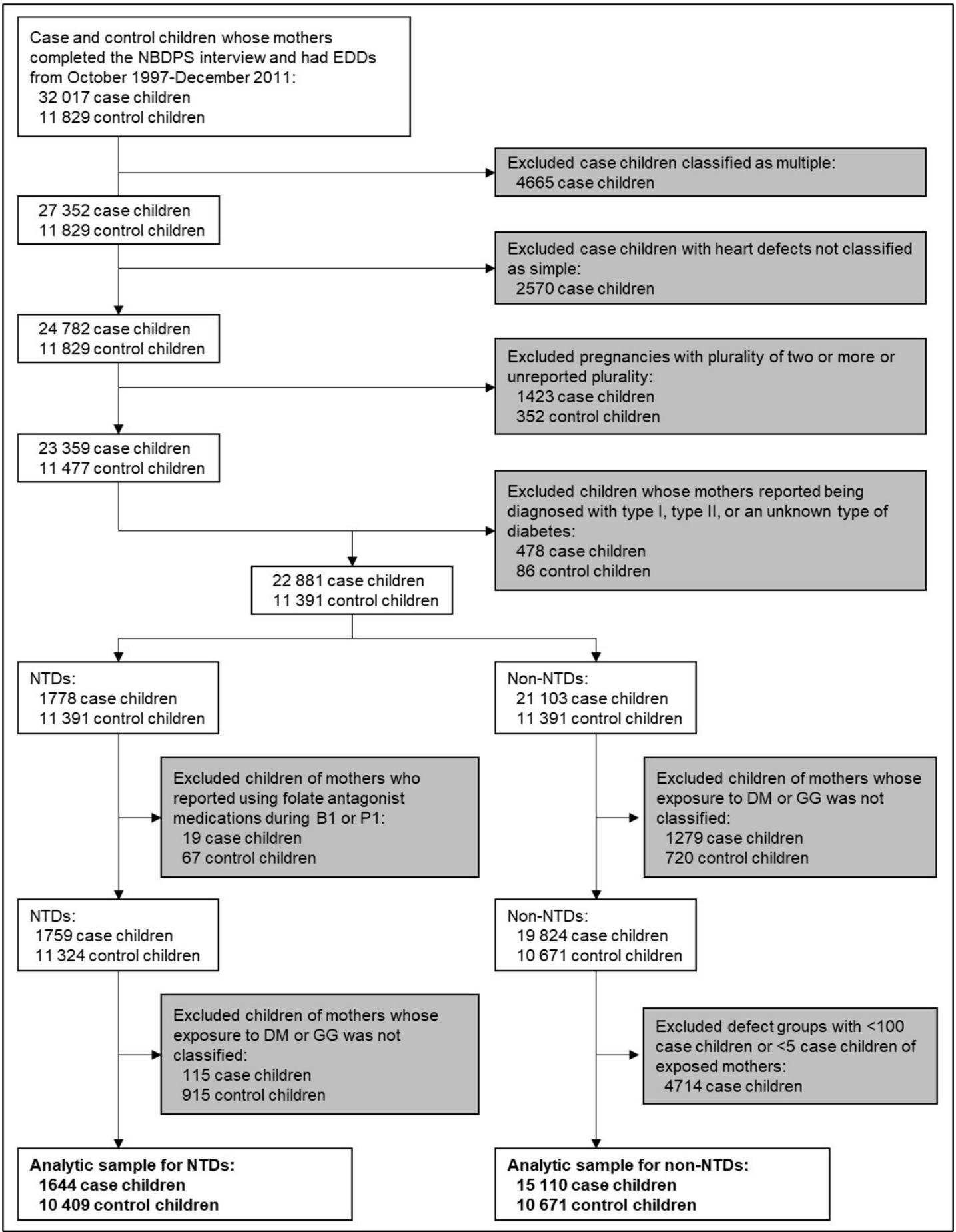

Figure 1 Sample exclusions for case and control children for analysis of maternal exposure to cough medications during early pregnancy, NBDPS, 1997-2011. B1, the month before pregnancy; DM, dextromethorphan; EDDs, estimated dates of delivery; GG, guaifenesin (glyceryl guaiacolate); NBDPS, National Birth Defects Prevention Study; NTDs, neural tube defects; P1, the first pregnancy month.

Among mothers included in analysis of NTDs, $52(3.2 \%)$ of 1644 mothers of case children and $208(2.0 \%)$ of 10 409 mothers of control children reported using cough medications containing DM, GG or both during B1P1. The respective totals for reported use during B1P3 in analysis of non-NTDs were 647 (4.3\%) of 15110 mothers of case children and $412(3.9 \%)$ of 10671 mothers of control children. Among mothers of case and control children who reported using medications containing DM alone during a critical exposure period, $96.8 \%$ reported using a cough medication that contained other active components (eg, antihistamines and analgesics); the proportion for GG alone was $7.9 \%$. In addition, $87.6 \%$ of mothers who reported using medications containing DM or GG also reported respiratory symptoms during a critical exposure period. 
Table 1 Distribution of selected child and maternal characteristics and exposures for analysis of NTDs, NBDPS, 1997-2011

\begin{tabular}{|c|c|c|}
\hline \multirow[b]{2}{*}{$\begin{array}{l}\text { Characteristic or } \\
\text { exposure }\end{array}$} & \multicolumn{2}{|c|}{ Individuals, No. (\%)* } \\
\hline & $\begin{array}{l}\text { Controls } \\
(n=10409)\end{array}$ & $\begin{array}{l}\text { All NTDs } \\
(n=1644)\end{array}$ \\
\hline \multicolumn{3}{|c|}{ Child characteristic } \\
\hline \multicolumn{3}{|c|}{ Sex } \\
\hline Male & 5309 (51.1) & $760(49.0)$ \\
\hline Female & 5089 (48.9) & $792(51.0)$ \\
\hline Missing & 11 & 92 \\
\hline \multicolumn{3}{|c|}{ First-degree family history of NTDs } \\
\hline Yes & $17(0.2)$ & $21(1.3)$ \\
\hline No & $10392(99.8)$ & $1623(98.7)$ \\
\hline Missing & 0 & 0 \\
\hline \multicolumn{3}{|l|}{ Study site } \\
\hline Arkansas & $1282(12.3)$ & $197(12.0)$ \\
\hline California & $1136(10.9)$ & $323(19.6)$ \\
\hline Georgia & 1098 (10.5) & 207 (12.6) \\
\hline lowa & $1149(11.0)$ & $191(11.6)$ \\
\hline Massachusetts & 1248 (12.0) & $85(5.2)$ \\
\hline New Jersey & $501(4.8)$ & $43(2.6)$ \\
\hline New York & $874(8.4)$ & $83(5.0)$ \\
\hline North Carolina & $894(8.6)$ & $164(10.0)$ \\
\hline Texas & $1221(11.7)$ & $203(12.3)$ \\
\hline Utah & $1006(9.7)$ & $148(9.0)$ \\
\hline Missing & 0 & 0 \\
\hline
\end{tabular}

\section{Maternal}

characteristic

\section{Race/ethnicity}

$\begin{array}{lcc}\text { Non-Hispanic white } & 5969(57.4) & 840(51.1) \\ \text { Non-Hispanic black } & 1143(11.0) & 142(8.6) \\ \text { Hispanic } & 2614(25.1) & 561(34.1) \\ \text { Other } & 676(6.5) & 101(6.1) \\ \text { Missing } & 7 & 0 \\ \text { Age at delivery (years) } & & \\ <25 & 3449(33.1) & 535(32.5) \\ 25-34 & 5528(53.1) & 885(53.8) \\ \geq 35 & 1432(13.8) & 224(13.6) \\ \text { Missing } & 0 & 0\end{array}$

Educational level at delivery (years)

\begin{tabular}{lcc}
$<12$ & $1736(17.2)$ & $319(19.9)$ \\
$12-15$ & $5067(50.2)$ & $873(54.6)$ \\
$\geq 16$ & $3298(32.7)$ & $407(25.5)$ \\
$\quad 308$ & 45 \\
$\begin{array}{l}\text { Missing } \\
\text { Prepregnancy BMI }\left(\mathrm{kg} / \mathrm{m}^{2}\right)\end{array}$ & \\
$<18.5$ & $549(5.5)$ & $56(3.7)$ \\
$18.5-24.9$ & $5359(54.1)$ & $735(48.3)$ \\
\hline
\end{tabular}

Continued
Table 1 Continued

\begin{tabular}{|c|c|c|}
\hline \multirow[b]{2}{*}{$\begin{array}{l}\text { Characteristic or } \\
\text { exposure }\end{array}$} & \multicolumn{2}{|c|}{ Individuals, No. (\%)* } \\
\hline & $\begin{array}{l}\text { Controls } \\
(n=10409)\end{array}$ & $\begin{array}{l}\text { All NTDs } \\
(n=1644)\end{array}$ \\
\hline $25.0-29.9$ & $2240(22.6)$ & 357 (23.5) \\
\hline$\geq 30.0$ & $1752(17.7)$ & $373(24.5)$ \\
\hline Missing & 509 & 123 \\
\hline \multicolumn{3}{|l|}{ Maternal exposure } \\
\hline \multicolumn{3}{|l|}{ Hypertension† } \\
\hline Yes & 918 (8.9) & $126(7.7)$ \\
\hline No & $9404(91.1)$ & $1503(92.3)$ \\
\hline Missing & 87 & 15 \\
\hline \multicolumn{3}{|l|}{ Cigarette smoking $\ddagger$} \\
\hline No active or passive & $7153(70.7)$ & $1102(68.8)$ \\
\hline Active only & $772(7.6)$ & $104(6.5)$ \\
\hline Passive only & $1199(11.9)$ & $265(16.5)$ \\
\hline Active and passive & $987(9.8)$ & $131(8.2)$ \\
\hline Missing & 298 & 42 \\
\hline \multicolumn{3}{|l|}{ Alcohol consumption $\ddagger$} \\
\hline Yes & $3551(35.1)$ & $490(30.6)$ \\
\hline No & $6557(64.9)$ & $1111(69.4)$ \\
\hline Missing & 301 & 43 \\
\hline \multicolumn{3}{|l|}{ Feverł } \\
\hline Yes & $493(5.1)$ & $116(7.8)$ \\
\hline No & $9126(94.9)$ & $1378(92.2)$ \\
\hline Missing & 790 & 150 \\
\hline \multicolumn{3}{|c|}{ Use of a supplement containing folic acidł } \\
\hline Yes & $5500(54.2)$ & $848(53.3)$ \\
\hline No & $4643(45.8)$ & $743(46.7)$ \\
\hline Missing & 266 & 53 \\
\hline
\end{tabular}

*Percentages within each column may not total 100 due to rounding.

†Diagnosed before or during pregnancy.

¥One month before pregnancy through the first month of pregnancy.

BMI, body mass index; NBDPS, National Birth Defects Prevention Study; NTDs, neural tube defects.

\section{Neural tube defects}

During B1P1, 1.7\% (28/1620 exposed +unexposed) of mothers of case children with NTDs reported using cough medications containing DM alone, $1.1 \%$ reported using medications containing GG alone and $0.4 \%$ reported using medications containing DM +GG (table 3). The respective proportions for mothers of control children were $1.2 \%, 0.6 \%$ and $0.2 \%$. For DM alone, we observed positive cORs with all NTDs, anencephaly and spina bifida with all CIs including the null. The corresponding aOR estimates were near the null with $95 \%$ CIs that included 1.0 for all NTDs and each NTD subtype. ORs for GG alone could only be estimated for all NTDs and spina 
Table 2 Distribution of selected child and maternal characteristics and exposures for analysis of non-NTDs, NBDPS, 1997-2011

\begin{tabular}{llc}
\hline & \multicolumn{2}{l}{ Individuals, No. (\%)* } \\
\cline { 2 - 3 } $\begin{array}{l}\text { Characteristic or } \\
\text { exposure }\end{array}$ & $\begin{array}{l}\text { Controls } \\
(\mathbf{n}=10671)\end{array}$ & $\begin{array}{l}\text { All non-NTDs } \\
(\mathbf{n}=\mathbf{1 5} 110)\end{array}$ \\
\hline $\begin{array}{l}\text { Child characteristic } \\
\text { Sex }\end{array}$ & & \\
\hline Male & $5443(51.1)$ & $9704(64.3)$ \\
Female & $5217(48.9)$ & $5390(35.7)$ \\
\hline Missing & 11 & 16
\end{tabular}

First-degree family history of same defect

\begin{tabular}{lcc} 
Yes & $--\dagger$ & $--\dagger$ \\
No & -- & -- \\
\hline Missing & 0 & 0 \\
\hline Study site & & \\
\hline Arkansas & $1318(12.4)$ & $1966(13.0)$ \\
\hline California & $1162(10.9)$ & $1861(12.3)$ \\
\hline Georgia & $1131(10.6)$ & $1574(10.4)$ \\
\hline lowa & $1178(11.0)$ & $1472(9.7)$ \\
\hline Massachusetts & $1268(11.9)$ & $2045(13.5)$ \\
\hline New Jersey & $517(4.8)$ & $828(5.5)$ \\
\hline New York & $892(8.4)$ & $1131(7.5)$ \\
\hline North Carolina & $916(8.6)$ & $1169(7.7)$ \\
\hline Texas & $1264(11.8)$ & $1305(8.6)$ \\
\hline Utah & $1025(9.6)$ & $1759(11.6)$ \\
\hline Missing & 0 & 0
\end{tabular}

\section{Maternal characteristic}

\begin{tabular}{|ccc|}
\hline Race/ethnicity & & \\
\hline Non-Hispanic white & $6127(57.5)$ & $9437(62.5)$ \\
\hline Non-Hispanic black & $1169(11.0)$ & $1267(8.4)$ \\
\hline Hispanic & $2672(25.1)$ & $3385(22.4)$ \\
\hline Other & $696(6.5)$ & $1019(6.7)$ \\
\hline Missing & 7 & 2 \\
\hline Age at delivery (years) & & \\
\hline$<25$ & $3532(33.1)$ & $5199(34.4)$ \\
\hline $25-34$ & $5666(53.1)$ & $7737(51.2)$ \\
\hline$\geq 35$ & $1473(13.8)$ & $2174(14.4)$ \\
\hline Missing & 0 & 0 \\
\hline Educational level at delivery (years) & \\
\hline$<12$ & $1765(17.0)$ & $2427(16.5)$ \\
\hline $12-15$ & $5211(50.3)$ & $7716(52.5)$ \\
\hline$\geq 16$ & $3381(32.6)$ & $4558(31.0)$ \\
\hline Missing & 314 & 409 \\
\hline Prepregnancy BMl (kg/m²) & \\
\hline$<18.5$ & $558(5.5)$ & $2607(18.0)$ \\
\hline $18.5-24.9$ & $5487(54.0)$ & $6719(5.7)$ \\
\hline $25.0-29.9$ & $2306(22.7)$ & $3302(22.9)$ \\
\hline 30.0 & $1810(17.8)$ & \\
\hline
\end{tabular}

Continued
Table 2 Continued

\begin{tabular}{|c|c|c|}
\hline \multirow[b]{2}{*}{$\begin{array}{l}\text { Characteristic or } \\
\text { exposure }\end{array}$} & \multicolumn{2}{|c|}{ Individuals, No. (\%)* } \\
\hline & $\begin{array}{l}\text { Controls } \\
(n=10671)\end{array}$ & $\begin{array}{l}\text { All non-NTDs } \\
(n=15110)\end{array}$ \\
\hline Missing & 510 & 663 \\
\hline \multicolumn{3}{|l|}{ Maternal exposure } \\
\hline \multicolumn{3}{|l|}{ Hypertension $\ddagger$} \\
\hline Yes & $944(8.9)$ & 1676 (11.2) \\
\hline No & $9640(91.1)$ & 13328 (88.8) \\
\hline Missing & 87 & 106 \\
\hline \multicolumn{3}{|l|}{ Cigarette smoking§ } \\
\hline No active or passive & $7253(70.0)$ & $9740(66.2)$ \\
\hline Active only & $783(7.6)$ & $1225(8.3)$ \\
\hline Passive only & $1292(12.5)$ & 1968 (13.4) \\
\hline Active and passive & 1039 (10.0) & $1779(12.1)$ \\
\hline Missing & 304 & 398 \\
\hline \multicolumn{3}{|l|}{ Alcohol consumption§ } \\
\hline Yes & $3818(36.8)$ & 5549 (37.7) \\
\hline No & $6546(63.2)$ & 9155 (62.3) \\
\hline Missing & 307 & 406 \\
\hline \multicolumn{3}{|l|}{ Fever§ } \\
\hline Yes & 1054 (10.7) & $1602(11.7)$ \\
\hline No & 8803 (89.3) & 12063 (88.3) \\
\hline Missing & 814 & 1445 \\
\hline \multicolumn{3}{|c|}{ Use of a supplement containing folic acid§ } \\
\hline Yes & $9100(87.5)$ & 12975 (87.9) \\
\hline No & $1296(12.5)$ & $1783(12.1)$ \\
\hline Missing & 275 & 352 \\
\hline
\end{tabular}

*Percentages within each column may not total 100 due to rounding.

†See online supplemental Tables 4-9 for frequencies for each defect.

‡Diagnosed before or during pregnancy.

§One month before pregnancy through the third month of pregnancy.

BMI, body mass index; NBDPS, National Birth Defects

Prevention Study; NTDs, neural tube defects.

bifida, and those for DM +GG could only be estimated for all NTDs. The cOR and aOR estimates for GG were similar, with the aOR estimates near twofold or higher for all NTDs $(\mathrm{aOR}=1.8 ; 95 \%$ CI 1.0 to 3.3$)$ and spina bifida $(\mathrm{aOR}=2.2 ; 95 \%$ CI 1.1 to 4.3$)$. The $\mathrm{cOR}$ for $\mathrm{DM}+\mathrm{GG}$ and all NTDs was higher than twofold; the corresponding aOR was somewhat attenuated (aOR=1.8; $95 \%$ CI 0.6 to 4.8$)$.

\section{Non-NTDs}

During B1P3, 2.2\% of mothers of case children with nonNTDs and $1.9 \%$ of mothers of control children reported using cough medications containing DM alone (table 4). Respective proportions were $1.7 \%$ and $1.6 \%$ for GG alone and $0.5 \%$ and $0.4 \%$ for DM +GG. We estimated ORs for 45 exposure-birth defect pairs. For 36 pairs, both cORs and 
aORs ranged from 0.5 to 1.6 with $95 \%$ CIs that included 1.0 , and for an additional three pairs, the cORs were near twofold or higher, but the aORs were attenuated with 95\% CIs that included 1.0. For the remaining six pairs, both cORs and aORs were near twofold or higher and included DM alone with hydrocephalus $(\mathrm{aOR}=1.9 ; 95 \% \mathrm{CI}$ 1.0 to 3.7 ), atrioventricular septal defect ( $\mathrm{aOR}=2.9 ; 95 \%$ CI 1.3 to 6.5$)$ and transverse limb deficiency $(\mathrm{aOR}=1.8$; 95\% CI 1.1 to 3.0); GG alone with small intestinal atresia/ stenosis $(\mathrm{aOR}=2.1 ; 95 \%$ CI 1.1 to 4.0$)$ and omphalocele $(\mathrm{aOR}=2.1 ; 95 \%$ CI 0.9 to 4.5$)$; and $\mathrm{DM}+\mathrm{GG}$ with gastroschisis $(\mathrm{aOR}=3.2 ; 95 \%$ CI 1.5 to 6.9 ). Our examination of maternal respiratory symptoms among mothers unexposed to DM or GG and NTDs or non-NTDs among children showed no differences in outcomes (online supplemental tables 10 and 11).

\section{DISCUSSION}

NBDPS data were used to examine associations between early pregnancy use of cough medications containing DM alone, GG alone or DM +GG with several major birth defects or defect groups. The aORs for DM alone with all NTDs and NTD subtypes were near the null; twofold positive estimates were observed for $\mathrm{DM}+\mathrm{GG}$ with all NTDs and those for GG alone with all NTDs and spina bifida. Among the 45 aORs for non-NTDs, six were near twofold or higher and included those for: DM alone with hydrocephalus, atrioventricular septal defect and transverse limb deficiency; GG alone with small intestinal atresia/stenosis and omphalocele; and DM +GG with gastroschisis.

Many estimates observed for NTDs or non-NTDs were imprecise; thus, our findings need to be interpreted cautiously. With the proportion (96.8\%) of mothers reportedly exposed to multicomponent cough medications containing DM but not GG, other active components may have contributed to positive associations observed for this exposure. Conversely, the proportion (7.9\%) of mothers reportedly exposed to multicomponent cough medications containing GG but not DM suggest other active components are less likely to explain observed associations with GG. Also, any positive associations identified may have been attributed to the respiratory symptoms reported rather than the use of DM or GG; however, analysis evaluating maternal respiratory symptoms among mothers unexposed to DM or GG produced aORs mostly near the null, suggesting minimal if any influence of confounding by indication. Lastly, with the number of associations estimated, any positive finding observed could have occurred by chance.

Our case-control study used the largest sample size to date to examine the safety of using OTC cough medications containing DM and/or GG during pregnancy. After exclusions, our proportions of control mothers exposed to DM alone $(1.9 \%)$ and GG alone $(1.6 \%)$ during B1P3 during 1997-2011 were similar to first trimester proportions $(2.1 \%$ and $1.7 \%$, respectively) reported by Werler 


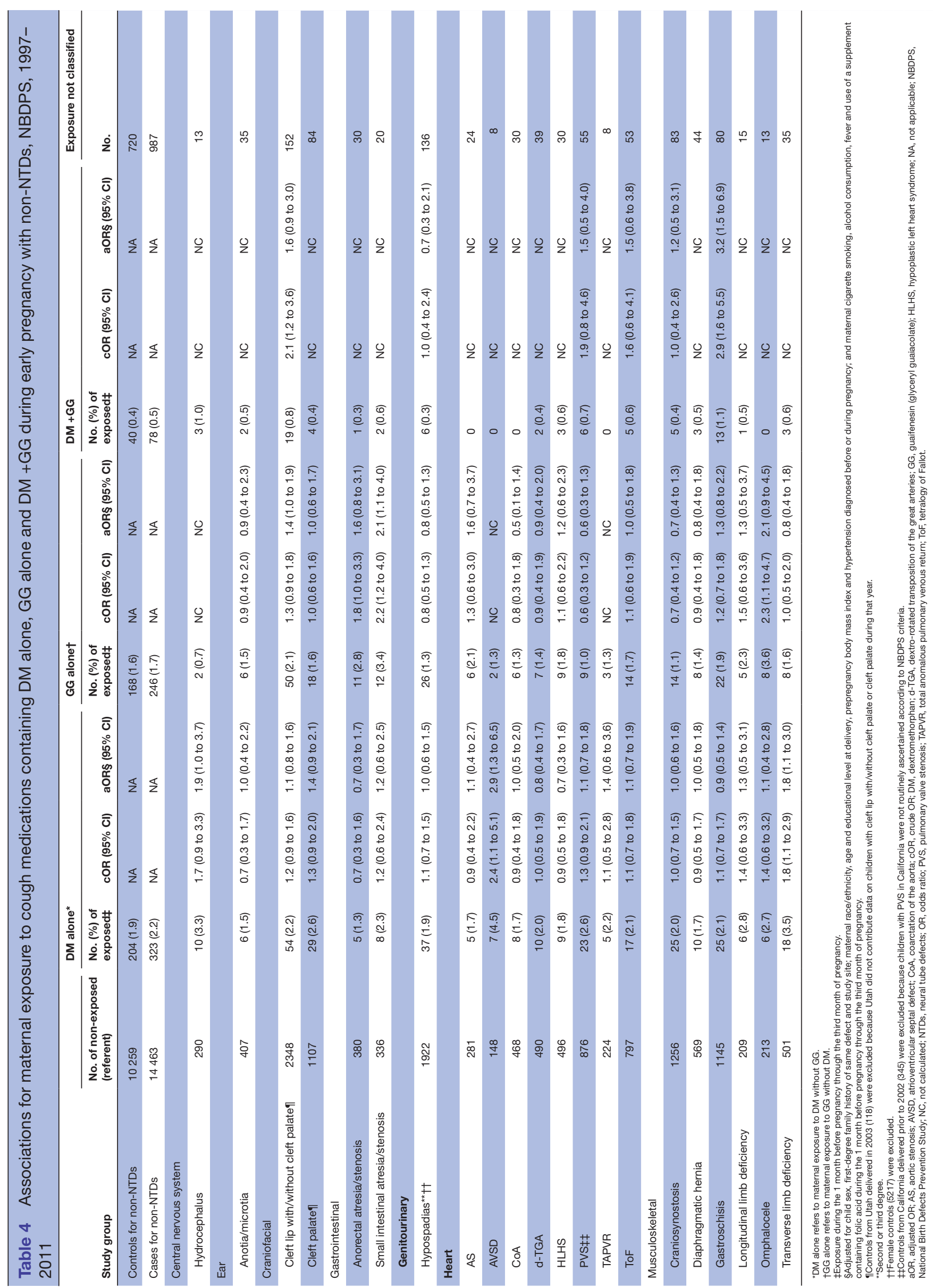


et al ${ }^{1}$ using NBDPS data for all control mothers during 1997-2003. However, with data collection for the NBDPS preceding the emergence of SARS-CoV-2 and COVID19 , use of these medications may be increasing. For DM alone, our associations for cleft palate and hydrocephalus were similar in direction but reduced in magnitude than those reported in a Spanish case-control study of DM. ${ }^{6}$ The lack of association observed for gastroschisis differed little from the weakly positive association observed in a North American case-control study of maternal medication use, ${ }^{8}$ and our association for hypospadias was increased from that reported in a previous NBDPS study of multiple risk factors for hypospadias that used data from fewer study years. ${ }^{9}$ For GG alone, associations observed with all NTDs and spina bifida tended to be consistent with a previous USA case-control study of maternal illness and medication use, although that study included NTDs beyond those included in NBDPS. ${ }^{11}$ The positive association for small intestinal atresia/stenosis differed from the inverse association reported in the North American study. ${ }^{8}$ Our associations for spina bifida and hydrocephalus were not comparable with those reported from a Finnish case-control study of any cough medication use (components not specified), ${ }^{12}$ and positive associations observed among the remainder of non-NTD defects with DM alone, GG alone or DM +GG were not directly comparable with those of previous studies.

Disruption of neural crest cells has been suggested as a possible teratogenic mechanism of DM in zebrafish and avian embryos, ${ }^{19}$ but this was not supported by our findings for the defects of neural crest origin that were examined. Xu $e t a l^{2}$ observed that zebrafish embryos exposed to higher doses of DM had shorter, malformed or undeveloped jaws and lordosis. Andaloro et al observed that avian embryos exposed to N-methyl-D-aspartate receptor antagonists, including DM, exhibited neural crest defects and NTDs; however, the relevance of these avian experiments to human prenatal exposure generated considerable debate. ${ }^{20-23}$ In a study of pregnant female rats, those administered GG had fetuses with decreased fetal weight and decreased skull, forelimb, hindlimb and tail lengths ${ }^{5}$; however, we did not observe an association between GG and limb deficiencies.

\section{Limitations and strengths of this study are important to consider}

Our study was limited by the small numbers of exposed mothers. Also, non-participation by about one-third of mothers identified may have increased the potential for selection bias; however, comparing selected characteristics of participants who were mothers of control children with characteristics of mothers from the base populations showed that both groups were similar for several maternal characteristics. ${ }^{24}$ Another limitation was that the primary data collected for exposure assessment included the medication name, timing and frequency of use but not the dose used, limiting the analysis to a dichotomous exposure. The primary data were collected by retrospective self-report, introducing the potential for missing or incorrect maternal reporting of exposure and for recall bias. To help reduce recall bias, NBDPS used a structured interview; such interviews, which include specific prompts for medications and corresponding treatments, can produce relatively complete postpregnancy reporting. ${ }^{25}$ Also, positive associations were not observed for each birth defect examined, nor were they observed for both DM alone and GG alone for a specific birth defect, suggesting little influence of recall bias in our findings.

A strength of our study was the large sample size, which had greater power than previous studies to estimate associations. Another strength was the use of active case finding and record-abstraction approaches by participating surveillance programmes; such approaches generally include multiple-source case finding to improve comprehensiveness of case ascertainment and systematic quality control procedures to ensure accuracy of case diagnoses. ${ }^{13}$ Additional strengths included the use of a systematic, detailed case-classification system to minimise variation in classification across sites, a systematic recruitment protocol and structured telephone interview for data collection to help reduce recall bias and centralised coding of active components for each reported medication. In addition, we developed a detailed exposure algorithm to systematically assign maternal exposure to cough medications during the critical exposure periods.

\section{CONCLUSIONS}

Our case-control study provides important, needed evidence regarding the relative safety of using cough medications that contain DM and/or GG in early pregnancy. Findings are largely reassuring regarding the safety of cough medications containing DM or GG, as maternal use of these medications showed positive associations with only a small number of birth defects. These associations, which are limited by small proportions of exposed mothers, may represent true signals or chance findings and warrant additional research. Because secondary data sources do not typically or systematically include information on exposure to OTC medications, primary data collection is likely needed for future studies of maternal use of cough medications containing DM and/or GG during early pregnancy and major birth defects. Such studies will need to include OTC exposures of currently available cough medications in large samples of pregnant women, along with improved collection of the timing and dose of these medications used during pregnancy.

Acknowledgements We are grateful to the families who participated in the National Birth Defects Prevention Study (NBDPS) and to the staff who conducted the study.

Contributors YC, AM and PR designed the study question. TB, KMC, MMW, AM and PR obtained study funding and supervised data acquisition. YC and AR had full access to the data and conducted statistical analysis and data replication. YC $A R$ and PR developed the initial draft of the manuscript. PAR supervised the data analysis and manuscript preparation. All authors contributed to data interpretation, 
critically reviewed and revised the manuscript for important intellectual content, and approved the final version to be submitted. PR is the guarantor.

Funding This work was supported by the USA Centers for Disease Control and Prevention through cooperative agreements under PA \#96043, PA \#02081, F0A \#DD09-001, F0A \#DD13-003 and NOF0 \#DD18-001 to the Centers for Birth Defects Research and Prevention participating in the National Birth Defects Prevention Study and the lowa Center for Birth Defects Research and Prevention U01 DD001035 and U01 DD001223 (PAR).

Disclaimer The findings and conclusions in this report are those of the authors and do not necessarily represent the official position of the USA Centers for Disease Control and Prevention, or the California Department of Public Health.

Competing interests AM serves on Biogen's Tecfidera Pregnancy Registry Advisory Committee.

Patient consent for publication Not applicable.

Ethics approval This study was approved by the University of lowa Institutional Review Board, and the NBDPS was approved by US Centers for Disease Control and Prevention and each participating site.

Provenance and peer review Not commissioned; externally peer reviewed.

The study questionnaires and process for accessing the data used in this study are described at https://www.cdc.gov/ncbddd/birthdefects/nbdps-public-accessprocedures.html. The code book and analytic code may be made available upon request.

Supplemental material This content has been supplied by the author(s). It has not been vetted by BMJ Publishing Group Limited (BMJ) and may not have been peer-reviewed. Any opinions or recommendations discussed are solely those of the author(s) and are not endorsed by BMJ. BMJ disclaims all liability and responsibility arising from any reliance placed on the content. Where the content includes any translated material, BMJ does not warrant the accuracy and reliability of the translations (including but not limited to local regulations, clinical guidelines, terminology, drug names and drug dosages), and is not responsible for any error and/or omissions arising from translation and adaptation or otherwise.

Open access This is an open access article distributed in accordance with the Creative Commons Attribution Non Commercial (CC BY-NC 4.0) license, which permits others to distribute, remix, adapt, build upon this work non-commercially, and license their derivative works on different terms, provided the original work is properly cited, appropriate credit is given, any changes made indicated, and the use is non-commercial. See: http://creativecommons.org/licenses/by-nc/4.0/.

\section{ORCID iD}

Paul Romitti http://orcid.org/0000-0001-5393-9984

\section{REFERENCES}

1 Werler MM, Mitchell AA, Hernandez-Diaz S, et al. Use of overthe-counter medications during pregnancy. Am J Obstet Gynecol 2005;193:771-7.

2 Xu Z, Williams FE, Liu M-C. Developmental toxicity of dextromethorphan in zebrafish embryos/larvae. J Appl Toxicol 2011;31:157-63.

3 Andaloro VJ, Monaghan DT, Rosenquist TH. Dextromethorphan and other $\mathrm{N}$-methyl-D-aspartate receptor antagonists are teratogenic in the avian embryo model. Pediatr Res 1998;43:1-7.
4 Brent RL. The teratogenicity of N-methyl-D-aspartate (NMDA) receptor antagonists. Pediatr Res 1998;44:415-7.

5 Shabbir A, Shamsi S, Shahzad M, et al. Evaluation of developmental toxicity of guaifenesin using pregnant female rats. Indian $J$ Pharmacol 2016;48:264-9.

6 Martínez-Frías ML, Rodríguez-Pinilla E. Epidemiologic analysis of prenatal exposure to cough medicines containing dextromethorphan: no evidence of human teratogenicity. Teratology 2001;63:38-41.

7 Aselton P, Jick H, Milunsky A, et al. First-Trimester drug use and congenital disorders. Obstet Gynecol 1985;65:451-5.

8 Werler MM, Sheehan JE, Mitchell AA. Maternal medication use and risks of gastroschisis and small intestinal atresia. Am J Epidemiol 2002;155:26-31.

9 Lind JN, Tinker SC, Broussard CS, et al. Maternal medication and herbal use and risk for hypospadias: data from the National birth defects prevention study, 1997-2007. Pharmacoepidemiol Drug Saf 2013;22:783-93.

10 Einarson A, Lyszkiewicz D, Koren G. The safety of dextromethorphan in pregnancy : results of a controlled study. Chest 2001;119:466-9.

11 Shaw GM, Todoroff K, Velie EM, et al. Maternal illness, including fever and medication use as risk factors for neural tube defects. Teratology 1998;57:1-7.

12 Granroth G. Defects of the central nervous system in Finland: III. disease and drugs in pregnancy. Early Hum Dev 1978;2:147-62.

13 Reefhuis J, Gilboa SM, Anderka M, et al. The National birth defects prevention study: a review of the methods. Birth Defects Res A Clin Mol Teratol 2015;103:656-69.

14 Rasmussen SA, Olney RS, Holmes LB, et al. Guidelines for case classification for the National birth defects prevention study. Birth Defects Res A Clin Mol Teratol 2003;67:193-201.

15 Tinker SC, Gibbs C, Strickland MJ, et al. Impact of time to maternal interview on interview responses in the National birth defects prevention study. Am J Epidemiol 2013;177:1225-35.

16 Kelley K, Kelley TP, Kaufman DW. The Slone drug dictionary: a research driven pharmacoepidemiology tool. Pharmacoepidemiol Drug Saf 2003:168-9.

17 Botto LD, Lin AE, Riehle-Colarusso T, et al. Seeking causes: classifying and evaluating congenital heart defects in etiologic studies. Birth Defects Res A Clin Mol Teratol 2007;79:714-27.

18 Hernández-Díaz S, Werler MM, Walker AM, et al. Neural tube defects in relation to use of folic acid antagonists during pregnancy. $A m \mathrm{~J}$ Epidemiol 2001;153:961-8.

19 van Gelder MMHJ, van Rooij IALM, Miller RK, et al. Teratogenic mechanisms of medical drugs. Hum Reprod Update 2010;16:378-94

20 Polifka JE, Shepard TH. Teratogenesis of dextromethorphan in the avian embryo. Pediatr Res 1998;44:415.

21 Rosenquist TH. Teratogenesis of dextromethorphan in the avian embryo. Pediatr Res 1998;44:416-7.

22 Brent RL, Shepard TH, Polifka JE. Response to Dr. Rosenquist's comments pertaining to the paper by Andaloro et al. ('98) "Dextromethorphan and other N-methyl-D-aspartate receptor antagonists are teratogenic in the avian embryo model" and letters to the editor by Polifka JE and Shepard TH ('98) and Brent RL ('98). Teratology 1999;60:61-2.

23 Holmes LB. Commentary. Pediatr Res 1999;45:286-7.

24 Cogswell ME, Bitsko RH, Anderka M, et al. Control selection and participation in an ongoing, population-based, case-control study of birth defects: the National birth defects prevention study. Am J Epidemiol 2009;170:975-85.

25 Mitchell AA, Cottler LB, Shapiro S. Effect of questionnaire design on recall of drug exposure in pregnancy. Am J Epidemiol 1986;123:670-6. 